\title{
Cost-Effectiveness of Rivaroxaban Versus Warfarin for Stroke Prevention in Atrial Fibrillation in the Belgian Healthcare Setting
}

\author{
Joris Kleintjens $\cdot$ Xiao Li $\cdot$ Steven Simoens $\cdot$ Vincent Thijs $\cdot$ Marnix Goethals \\ Ernst R. Rietzschel · Yumi Asukai · Ömer Saka · Thomas Evers • \\ Petra Faes $\cdot$ Stefaan Vansieleghem $\cdot$ Mimi De Ruyck
}

Published online: 13 September 2013

(c) The Author(s) 2013. This article is published with open access at Springerlink.com

\begin{abstract}
Background Warfarin, an inexpensive drug that has been available for over half a century, has been the mainstay of anticoagulant therapy for stroke prevention in patients with atrial fibrillation (AF). Recently, rivaroxaban, a novel oral anticoagulant (NOAC) which offers some distinct advantages over warfarin, the standard of care in a world without NOACs, has been introduced and is now recommended by international guidelines.

Objective The aim of this study was to evaluate, from a Belgian healthcare payer perspective, the cost-effectiveness
\end{abstract}

Electronic supplementary material The online version of this article (doi:10.1007/s40273-013-0087-9) contains supplementary material, which is available to authorized users.

\section{J. Kleintjens · X. Li · Ö. Saka}

Deloitte Health Economics and Outcomes Research Group,

Brussels, Belgium

\section{S. Simoens}

Department of Pharmaceutical and Pharmacological Sciences,

KU Leuven, Leuven, Belgium

\section{Thijs}

Laboratory of Neurobiology, Vesalius Research Center, VIB, Leuven, Belgium

\section{Thijs}

Experimental Neurology (Department of Neurosciences) and Leuven Research Institute for Neuroscience and Disease (LIND), University of Leuven (KU Leuven), Leuven, Belgium

\section{Thijs}

Department of Neurology, University Hospitals Leuven, Leuven, Belgium

M. Goethals

Mariaziekenhuis Noord-Limburg, Overpelt, Belgium of rivaroxaban versus use of warfarin for the treatment of patients with non-valvular AF at moderate to high risk.

Methods A Markov model was designed and populated with local cost estimates, safety-on-treatment clinical results from the pivotal phase III ROCKET AF trial and utility values obtained from the literature.

Results Rivaroxaban treatment was associated with fewer ischemic strokes and systemic embolisms (0.308 vs. 0.321 events), intracranial bleeds (0.048 vs. 0.063$)$, and myocardial infarctions (0.082 vs. 0.095$)$ per patient compared with warfarin. Over a lifetime time horizon, rivaroxaban led to a reduction of 0.042 life-threatening events per patient, and increases of 0.111 life-years and 0.094 qualityadjusted life-years (QALYs) versus warfarin treatment. This resulted in an incremental cost-effectiveness ratio of

\section{E. R. Rietzschel}

Department of Internal Medicine (Cardiovascular Diseases),

Faculty of Medicine and Health Sciences, Ghent University and Ghent University Hospital, Ghent, Belgium

\section{E. R. Rietzschel}

Department of Public Health, Faculty of Medicine and Health Sciences, Ghent University and Ghent University Hospital, Ghent, Belgium

Y. Asukai

IMS Health, London, UK

T. Evers

Global Market Access/HEOR, Bayer HealthCare, Wuppertal, Germany

P. Faes $\cdot$ S. Vansieleghem $\cdot$ M. De Ruyck $(\square)$

Market Access Department, Bayer HealthCare, J.E.

Mommaertslaan 14, 1831 Diegem (Machelen), Belgium

e-mail: mimi.deruyck@bayer.com 
$€ 8,809$ per QALY or $€ 7,493$ per life-year gained. These results are based on valuated data from 2010. Sensitivity analysis indicated that these results were robust and that rivaroxaban is cost-effective compared with warfarin in $87 \%$ of cases should a willingness-to-pay threshold of $€ 35,000 / \mathrm{QALY}$ gained be considered.

Conclusions The present analysis suggests that rivaroxaban is a cost-effective alternative to warfarin therapy for the prevention of stroke in patients with $\mathrm{AF}$ in the Belgian healthcare setting.

\section{Key Points for Decision Makers}

- A large proportion of patients with atrial fibrillation (AF) and moderate to high risk of stroke do not receive thromboprophylaxis or are not optimally controlled with vitamin K antagonists (VKAs).

- Rivaroxaban (Xarelto ${ }^{\circledR}$ ), a once-daily agent, is one of the novel oral anticoagulants that are now recommended by recent international guidelines as broadly preferable to VKAs for patients with non-valvular AF.

- The present analysis suggests that rivaroxaban is a costeffective alternative to warfarin therapy for the prevention of stroke in patients with $\mathrm{AF}$ in the Belgian healthcare setting.

\section{Introduction}

Atrial fibrillation (AF) is associated with an increase in the risk of ischemic stroke by a factor of four to five and accounts for $15-25 \%$ of all stroke cases $[1,2]$. Stroke is a major cause of long-term disability and death. According to the WHO, in 2004, stroke and other cerebrovascular diseases accounted for 5.7 million deaths worldwide ( $9.7 \%$ of total) and was the second leading cause of death after coronary heart disease $[3,4]$. In Belgium, the gender- and age-adjusted incidence rate for first-ever and recurrent stroke is estimated to be 185 per 100,000 inhabitants per year [5]. Given that about one-fifth of all stroke cases are attributable to AF [6], it is thought that $\mathrm{AF}$ causes 4,000 stroke cases per year in Belgium.

An individual's risk of AF-related stroke can be estimated with $\mathrm{CHADS}_{2}$ scores (scale ranging from 0 to 6 , with a greater risk of stroke indicated by higher scores) and reduced by two-thirds with effective anticoagulation. Vitamin K antagonists (VKAs), such as warfarin, have been the mainstay of anticoagulant therapy for over half a century [7]. In Belgium, most AF patients with moderate to high risk of stroke $\left(\mathrm{CHADS}_{2}\right.$ score $\left.\geq 2\right)$ are currently treated with VKA therapy ( $\pm 50 \%$ of patients) or aspirin
$( \pm 25 \%)$, or receive other non-pharmacological treatments $[8,9]$. There are, however, some disadvantages associated with VKA therapy. These agents have a slow onset of action and possess a narrow therapeutic window. Due to pharmacogenetic variability and the various interactions VKAs have with both food and other drugs, it tends to be difficult to maintain a patient within the optimal international normalized ratio (INR) range of 2.0-3.0. As a result, there is a need for frequent and lifelong blood monitoring [10].

Recently, novel oral anticoagulants (NOACs), rivaroxaban (once daily), dabigatran etexilate (twice daily), apixaban (twice daily) have been approved as possible alternatives to VKA therapy. Rivaroxaban $\left(\right.$ Xarelto $\left.^{\circledR}\right)$ is a highly selective, oral, once daily, direct factor Xa inhibitor that has shown a favourable risk-benefit profile compared with warfarin in the prevention of stroke and systemic embolism events. In the phase III study (ROCKET AF), rivaroxaban demonstrated a $21 \%$ risk reduction in event rate for stroke and systemic embolism (hazard ratio [HR] 0.79 ; $95 \%$ CI $0.66-0.96 ; p<0.001$ for non-inferiority) while on-treatment compared with warfarin, and a significant reduction in the most serious complications of warfarin therapy, i.e. intracranial haemorrhage and fatal bleeding [11]. Since then the product has been approved for stroke prevention in non-valvular AF by both the US FDA and the European Medicines Agency (EMA), and in many countries worldwide. Dabigatran etexilate and apixaban also showed a favourable risk-benefit profile compared with warfarin in their phase III trials (RE-LY and ARISTOTLE, respectively) $[12,13]$. On the basis of the clinical evidence that has arisen in the last few years, the most recent version of the European Society of Cardiology guidelines for the management of AF now recommends the NOACs as broadly preferable to VKAs in the vast majority of patients with non-valvular AF, when used as studied in the clinical trials [14].

Warfarin therapy is both effective and inexpensive, but treatment with rivaroxaban offers some distinct advantages over warfarin. Therefore, the aim of the present study was to evaluate the cost-effectiveness of rivaroxaban versus warfarin for the prevention of stroke in patients with $\mathrm{AF}$ at moderate $\left(\mathrm{CHADS}_{2}\right.$ score $\left.=2\right)$ to high risk $\left(\mathrm{CHADS}_{2}\right.$ score $\left.>2\right)$ in the Belgian healthcare setting. To our knowledge, this is one of the very first studies evaluating this hypothesis.

\section{Methods}

\subsection{Model Structure}

For this study, a Markov cost-effectiveness model was designed that can be used by decision makers to systematically assess the comparative costs and outcomes of a 


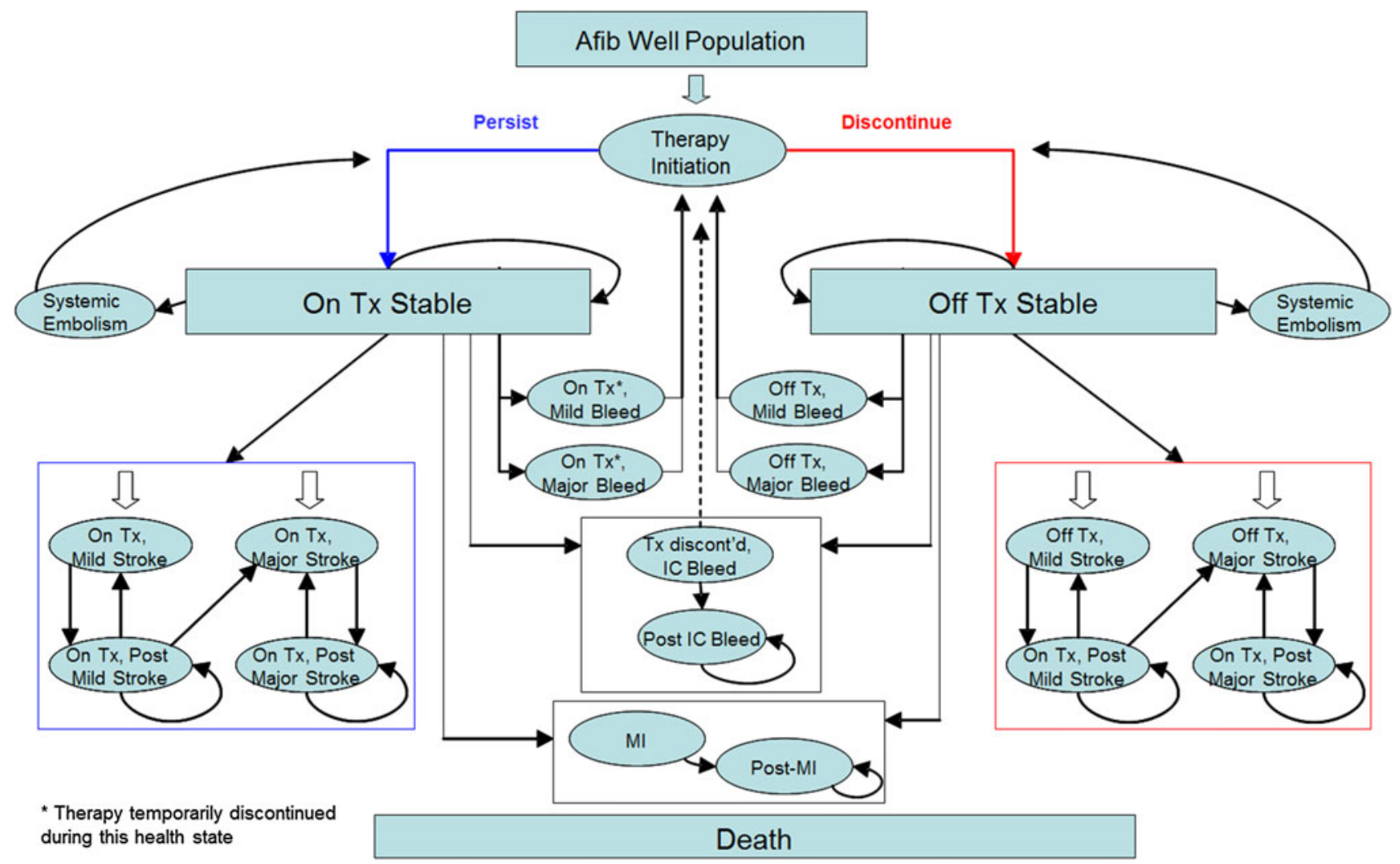

Fig. 1 Structure of the model. Afib atrial fibrillation, IC intracranial, MI myocardial infarction, Tx treatment

new treatment compared with warfarin (Fig. 1). Patients with a mean age of 73 years and suffering from non-valvular $\mathrm{AF}$ at moderate $\left(\mathrm{CHADS}_{2}\right.$ score $\left.=2\right)$ to high risk of stroke $\left(\mathrm{CHADS}_{2}\right.$ score $=3$ or higher $)$ enter the model and receive chronic treatment with either rivaroxaban (new treatment, $15-20 \mathrm{mg}$ oral tablet, once daily) or doseadjusted warfarin (comparator treatment, target INR of 2.5). In both cases, patients received aspirin after discontinuation of the initial treatment. The evaluation was carried out from the perspective of the Belgian health care payer (i.e. National Institute for Health and Disability Insurance and patients).

The model was populated with clinical data from the pivotal head-to-head phase III ROCKET AF trial and local cost estimates in order to calculate an incremental costeffectiveness ratio (ICER) of rivaroxaban compared with warfarin. Direct comparisons with dabigatran or apixaban were not done as head-to-head trials do not exist and both molecules were not yet approved at the time of the ROCKET trial. The cycle length of the model was 3 months and patients progressed between states according to the event rates as observed in the trial. Patients experiencing an ischemic stroke were presumed to continue with their anticoagulation therapy if they were already on therapy and/ or to (re)-initiate the therapy if they had discontinued. Modified Rankin Scores (mRS), a commonly used scale for measuring the degree of disability or dependence in the daily activities, were recorded in the ROCKET AF trial and used to categorize strokes as either minor (mRS score 0-2) or major (mRS score 3-5). In the post-stroke, post-myocardial infarction and post-intracranial bleed states, patients continued to be at risk of experiencing secondary events according to the risk profile of the drug they had been reinitiated on. These secondary events are minor bleeds, major extracranial bleed, myocardial infarction and systemic embolisms. The patients will not be sent to the respective secondary health states but instead will be given a pay-off corresponding to the cost and (dis)utility of those acute events. If the utility of the secondary event is higher than the utility of the primary health state, the utility from the primary health state will be applied. This is to prevent the eventual return of these patients to a less severe health state (e.g. from post-stroke to stable $\mathrm{AF}$ ) where the utility and cost consequences of the more severe health states would not be applied. The main complications, classified as either transient (non-boxed states in Fig. 1) or permanent (boxed) health states, were death, ischemic stroke, systemic embolism, bleeding and myocardial infarction. Bleeding events were categorized as major extracranial, clinically relevant non-major (CRNM) extracranial, and intracranial as defined in the manuscript describing the rationale and design of the ROCKET AF study [15]. 


\subsection{Clinical Effectiveness and Treatment} Discontinuation

The main clinical data inputs were based on the safety on treatment results of the ROCKET AF trial and are presented in Table 1. ROCKET AF was found to be the only single trial that provides head-to-head clinical evidence on efficacy and safety of rivaroxaban in stroke prevention in AF compared with adjusted-dose warfarin. Rivaroxaban was associated with significant reductions in intracranial haemorrhage ( 0.5 vs. $0.7 \% ; p=0.02)$ and fatal bleeding (0.2 vs. $0.5 \% ; p=0.003)$. As there is discussion on the most appropriate statistical method to evaluate results of non-inferiority trials [16, 17], results based on the intention-to-treat population are also presented. Baseline event rates were obtained from the warfarin arm of the trial and converted into quarterly rates for use in the modelling analysis as described by Briggs et al. [18]. Relative risks of events from ROCKET AF for rivaroxaban were applied to these event rates observed with warfarin. For example, the baseline risk of ischaemic stroke was $1.42 \%$ per year in the warfarin arm of the study, which was converted into a quarterly rate of $0.36 \%$ [11]. For rivaroxaban, this rate was multiplied by a relative risk of 0.94 , resulting in a quarterly event rate of $0.34 \%$. Event rates for systemic embolism, bleeding events, and myocardial infarction were derived in an identical manner. Background mortality, based on Belgian life tables [19], and mortality specific to the clinical events were included in the model (Table 2). Estimates for event-related mortality were based on results of the ROCKET AF study, except for the long-term mortality rates following major stroke [2] and myocardial infarction [20] which were obtained from the literature. Patients could transition to the death health state from all other health states. It was assumed there were no event-related case fatalities in the minor stroke, post-minor stroke, CRNM extracranial bleed, post-CRNM and post-major extracranial bleed, and systemic embolism health states. Treatment

Table 1 Overview clinical input data $(95 \% \mathrm{CI})$

\begin{tabular}{|c|c|c|}
\hline Event (source) & $\begin{array}{l}\text { Baseline risk [\%] } \\
\text { (3 months) }\end{array}$ & $\begin{array}{l}\text { RR rivaroxaban } \\
\text { vs. warfarin }\end{array}$ \\
\hline Ischemic stroke [11] & $0.36(0.27-0.45 \%)$ & $0.94(0.75-1.17)$ \\
\hline Of which major [31] & $59.00(41.84-62.66 \%)$ & - \\
\hline Of which minor & $41.00(37.34-58.16 \%)$ & - \\
\hline Systemic embolism [11] & $0.05(0.00-0.76 \%)$ & $0.23(0.09-0.61)$ \\
\hline $\begin{array}{l}\text { Extracranial CRNM } \\
\text { bleed [11] }\end{array}$ & $2.97(1.79-5.04 \%)$ & $1.04(0.96-1.13)$ \\
\hline $\begin{array}{l}\text { Extracranial major } \\
\text { bleed [11] }\end{array}$ & $0.69(0.24-1.90 \%)$ & $1.14(0.98-1.33)$ \\
\hline Intracranial bleed [11] & $0.19(0.03-1.04 \%)$ & $0.67(0.47-0.93)$ \\
\hline Myocardial infarction [11] & $0.28(0.05-1.22 \%)$ & $0.81(0.63-1.06)$ \\
\hline
\end{tabular}

$C R N M$ clinically relevant non-major, $R R$ relative risk discontinuation rates for rivaroxaban $(8.90 \%$ in the initial and $4.39 \%$ in subsequent cycles) and warfarin $(8.00 \%$ in the initial and $4.46 \%$ in subsequent cycles) were also derived from the ROCKET AF trial.

\subsection{Drug and Event Costs}

Three relevant cost categories were identified: drug acquisition costs, drug administration/monitoring costs, and events costs (Table 3; Online Resource 1). Based on the market shares and pack sizes of the brands that are locally available, a weighted average drug cost of $€ 0.31$ and $€ 0.07$ was estimated for VKAs and aspirin, respectively. For rivaroxaban, an average cost of $€ 2.70$ per tablet was assumed. When patients are initiated on warfarin therapy, it is recommended that they visit their physician regularly to make the dose adjustments required to maintain the target INR of 2.5 (typical target range is 2.0-3.0). Based on a report of the Belgian health care knowledge centre $(\mathrm{KCE})$, it was assumed that these patients have 15 general practitioner (GP) visits ( $€ 29$ per visit) and INR laboratory tests ( $€ 15.8$ per test) per year, or 3.75 per Markov cycle [21]. For aspirin and rivaroxaban, the model assumes that patients would visit their GP two times per year (range 0-8 GP visits) as no monitoring is required for these therapies. At the time the present pharmacoeconomic evaluation was prepared for submission to local reimbursement authorities, costs were inflated to the year 2010 using the appropriate annual Health Index figures as recommended by the Belgian KCE guidelines [22].

\subsection{Health-Related Outcomes}

A systematic search was performed to identify health state utility values in AF, stroke, post-stroke, embolism, myocardial infarction, and bleeding events occurring in a nonvalvular AF population. The baseline utility for an untreated AF patient aged 73 years was set at 0.799 (Table 4). Utility scores specific to Belgium were not identified during the search. Although it is generally accepted that the need for constant monitoring can adversely affect the quality of life [23-25], a disutility for warfarin treatment was not applied in the base-case analysis. Table 4 shows the health state utility values and ranges used in the analysis.

\subsection{Analysis}

The model's primary outcomes were the number of lifeyears, quality-adjusted life-years (QALYs), and lifethreatening events per patient. In the base-case costeffectiveness analysis, an ICER was calculated as the difference in costs divided by the difference in outcomes 
Table 2 Mortality rates $(95 \% \mathrm{CI})$

\begin{tabular}{ll}
\hline Health state (source) & $\begin{array}{l}\text { Event-related mortality } \\
\text { rate per 3-month cycle [\%] }\end{array}$ \\
\hline Major stroke [32] & $12.6(9.4-15.7 \%)$ \\
Post-major stroke [2, 32] & $2.63(0.91-13.50 \%)$ \\
Minor stroke & $\mathrm{N} / \mathrm{A}^{\mathrm{a}}$ \\
Systemic embolism & $\mathrm{N} / \mathrm{A}^{\mathrm{a}}$ \\
Major extracranial bleed [32] & $1.55(1.16-1.94 \%)$ \\
Intracranial bleed [32] & $38.85(29.14-48.56 \%)$ \\
Post-intracranial bleed [32] & $2.63(0.91-13.5 \%)^{\mathrm{b}}$ \\
Myocardial infarction [32] & $9.69(7.27-12.11 \%)$ \\
Post-myocardial infarction [20, 32] & $2.68(0-6.75 \%)$ \\
\hline
\end{tabular}

N/A not applicable

${ }^{\text {a }}$ It is assumed minor stroke and systemic embolism have a casefatality of $0 \%$ and thus mortality rate is equal to that in the general population

b Assumed identical to post-major stroke mortality rate

associated with the two treatments. In accordance with local guidelines, future costs were discounted at a rate of $3 \%$, and future outcomes were discounted at a rate of $1.5 \%$ [22]. In order to fully incorporate the costs and outcomes of $\mathrm{AF}$, the time horizon was set to describe the lifetime of treated patients. A one-way sensitivity analysis and a probabilistic sensitivity analysis (PSA) were performed to evaluate the impact a change in input variables may have on the model's results. In these analyses, a beta distribution was used for model transition probabilities (event rates) and utility parameters, while relative risk parameters and costs were assumed to have a log-normal distribution, and a gamma distribution was used for resource use [18]. Base-case estimates were adjusted based on $95 \%$ CIs from the analysis of the ROCKET AF trial. Alternatively, point estimates for costs varied by $25 \%$, which was considered sufficient variation to capture relevant uncertainty. Both the development and the adaptation of this model to the Belgian environment were validated by a number of leading clinicians and health economists. During the validation process, the model's structure, logic, input data, key assumptions, mathematical steps and functionalities were thoroughly tested.

\section{Results}

\subsection{Base-Case Analysis}

In the base-case analysis, rivaroxaban treatment was associated with fewer ischemic strokes and systemic embolisms ( 0.308 vs. 0.321 events per patient), intracranial bleeds (0.048 vs. 0.063$)$, and myocardial infarctions $(0.082$ vs. 0.095) compared with warfarin treatment. Consequently, patients treated with rivaroxaban gained more

Table 3 Overview of drug, monitoring, and event costs [33, 34; Online Resource 1]

\begin{tabular}{|c|c|c|c|}
\hline Item & Drug costs (per tablet) $[€]$ & & $\begin{array}{l}\text { Consultation }{ }^{\mathrm{e}} \text { and INR monitoring } \\
\text { costs (per visit) }[€]\end{array}$ \\
\hline Rivaroxaban $^{\mathrm{a}}$ & 2.70 & & 29.08 \\
\hline Vitamin $\mathrm{K}$ antagonist $\mathrm{t}^{\mathrm{b}}$ & 0.31 & & 44.85 \\
\hline Aspirin $^{b}$ & 0.07 & & 29.08 \\
\hline Event $^{c}$ & Acute (per event) [€] & $\begin{array}{l}\text { Rehabilitation }^{\mathrm{f}} \\
\text { (per event) }[€]\end{array}$ & $\begin{array}{l}\text { Long-term follow-up } \\
\text { (per } 3 \text { months) }[€]\end{array}$ \\
\hline Minor stroke & 5,946 & 3,204 & 244 \\
\hline Major stroke & 12,247 & 17,734 & 2,216 \\
\hline Systemic embolism & 5,124 & - & - \\
\hline CRNM extracanial bleed & 23 & - & - \\
\hline Major extracanial bleed & 3,510 & - & - \\
\hline Intracranial bleed ${ }^{\mathrm{d}}$ & 7,699 & 17,734 & 2,216 \\
\hline Myocardial infarction & 7,891 & - & - \\
\hline
\end{tabular}

CRNM clinically relevant non-major, INR international normalized ratio

a Assuming 5 and $95 \%$ of tablets from the 28- (€98.82) and 98-tablet (€260.23) drug packages sizes, respectively

b Based on market share and prices of locally available brands

c The range of event costs tested in sensitivity analyses was $\pm 25 \%$ of the mean

${ }^{\mathrm{d}}$ Costs of rehabilitation and long-term follow-up were assumed identical, as for major stroke

e Includes home consultations

${ }^{\mathrm{f}}$ Based on unpublished results, (Putman K, personal communication) 
Table 4 Overview of utility values (range)

\begin{tabular}{|c|c|c|c|c|c|c|}
\hline \multirow[t]{2}{*}{ Description } & \multicolumn{2}{|c|}{$\begin{array}{l}\text { Currently value in } \\
\text { the model }\end{array}$} & \multirow[t]{2}{*}{ Distribution (SD) } & \multirow[t]{2}{*}{ Reference } & \multirow[t]{2}{*}{ Population } & \multirow[t]{2}{*}{ Country } \\
\hline & Mean & Range & & & & \\
\hline Stable—not on therapy & 0.799 & $0.635-1$ & $\begin{array}{l}\text { Beta }(a=14.0 \\
\quad b=3.5)\end{array}$ & Dagres et al. [35] & $\begin{array}{l}\text { Patients with atrial fibrillation } \\
\text { enrolled in the Euro Heart } \\
\text { Survey on Atrial Fibrillation, } \\
\text { mean age } 67 \text { years }\end{array}$ & Europe \\
\hline Stable_-on warfarin therapy & 0.799 & $0.635-1$ & N/A & Dagres et al. [35] & $\begin{array}{l}\text { Patients with atrial fibrillation } \\
\text { enrolled in the Euro Heart } \\
\text { Survey on Atrial Fibrillation, } \\
\text { mean age } 67 \text { years }\end{array}$ & Europe \\
\hline $\begin{array}{l}\text { Utility decrement used for } \\
\text { warfarin }\end{array}$ & 1.000 & $0.920-1$ & N/A & Robinson et al. [36] & $\begin{array}{l}\text { Patients with atrial fibrillation, } \\
\text { male and female, mean age } \\
73 \text { years }\end{array}$ & UK \\
\hline Stable—on other therapy & 0.799 & $0.635-1$ & N/A & $\begin{array}{l}\text { Assumed }=\text { not on } \\
\text { therapy }\end{array}$ & N/A & N/A \\
\hline $\begin{array}{l}\text { Stable-initiating warfarin } \\
\text { therapy }\end{array}$ & 0.799 & $0.635-1$ & N/A & $\begin{array}{l}\text { Assumed }=\text { stable } \\
\text { on warfarin }\end{array}$ & N/A & N/A \\
\hline $\begin{array}{l}\text { Utility decrement used for } \\
\text { initiating warfarin }\end{array}$ & 1.000 & $0.920-1$ & N/A & Robinson et al. [36] & $\begin{array}{l}\text { Patients with atrial fibrillation, } \\
\text { male and female, mean age } \\
73 \text { years }\end{array}$ & UK \\
\hline \multicolumn{7}{|l|}{ Embolic events } \\
\hline Minor stroke & 0.641 & $0.550-0.660$ & $\begin{array}{l}\text { Beta }(a=187 \\
\quad b=105)\end{array}$ & Robinson et al. [36] & $\begin{array}{l}\text { Patients with atrial fibrillation, } \\
\text { male and female, mean age } \\
73 \text { years }\end{array}$ & UK \\
\hline Post-minor stroke & 0.727 & $0.538-0.772$ & $\begin{array}{l}\text { Beta }(a=40 \\
\quad b=15)\end{array}$ & Hallan et al. [37] & $\begin{array}{l}\text { Stroke survivors, mean age } \\
65 \text { years }\end{array}$ & Norway \\
\hline Major stroke & 0.189 & $0.142-0.236$ & $\begin{array}{l}\text { Beta }(a=50 \\
\quad b=213)\end{array}$ & Robinson et al. [36] & $\begin{array}{l}\text { Patients with atrial fibrillation, } \\
\text { male and female, mean age } \\
73 \text { years }\end{array}$ & UK \\
\hline Post-major stroke & 0.487 & $0.078-0.710$ & $\begin{array}{l}\text { Beta }(a=4.2 \\
\quad b=4.4)\end{array}$ & Hallan et al. [37] & $\begin{array}{l}\text { Stroke survivors, mean age } \\
65 \text { years }\end{array}$ & Norway \\
\hline Systemic embolism & 0.679 & $0.660-0.692$ & $\begin{array}{l}\text { Beta }(a=2251 \\
\quad b=1061)\end{array}$ & Sullivan et al. [38] & $\begin{array}{l}\text { Patients with systemic embolic } \\
\text { event (ICD-9 444) }\end{array}$ & US \\
\hline \multicolumn{7}{|l|}{ Bleeding events } \\
\hline Minor bleed & 0.796 & $0.794-0.789$ & $\begin{array}{l}\text { Beta }(a=34 \\
\quad b=9)\end{array}$ & Sullivan et al. [38] & $\begin{array}{l}\text { Patients with systemic embolic } \\
\text { event (ICD-9 444) }\end{array}$ & US \\
\hline Major bleed & 0.618 & $0.590-0.645$ & $\begin{array}{l}\text { Beta }(a=762 \\
\quad b=470)\end{array}$ & Sullivan et al. [38] & $\begin{array}{l}\text { Patients with systemic embolic } \\
\text { event (ICD-9 444) }\end{array}$ & US \\
\hline Intracranial bleed & 0.600 & $0.020-0.635$ & $\begin{array}{l}\text { Beta }(a=1.7 \\
\quad b=1.1)\end{array}$ & $\begin{array}{l}\text { Lenert and Soetikno } \\
\text { [39] }\end{array}$ & $\begin{array}{l}\text { Deep venous thrombosis, } \\
20-40 \text { for female volunteers }\end{array}$ & US \\
\hline Post-intracranial bleed & 0.740 & $0.078-0.772$ & $\begin{array}{l}\text { Beta }(a=3.8 \\
\quad b=1.3)\end{array}$ & Haacke et al. [40] & $\begin{array}{l}\text { Patients with an ischemic, } \\
\text { transient ischemic or } \\
\text { hemorrhagic stroke, mean } \\
\text { age } 74.6 \text { years }\end{array}$ & Germany \\
\hline \multicolumn{7}{|l|}{ Myocardial infarction events } \\
\hline Myocardial infarction & 0.667 & $0.501-0.799$ & $\begin{array}{l}\text { Beta }(a=25 \\
\quad b=12)\end{array}$ & Robinson et al. [42] & $\begin{array}{l}\text { Patients with acute myocardial } \\
\text { infarction }\end{array}$ & UK \\
\hline Post-myocardial infarction & 0.703 & $0.528-0.799$ & $\begin{array}{l}\text { Beta }(a=30 \\
\quad b=13)\end{array}$ & Sanders et al. [41] & $\begin{array}{l}\text { Patients with past myocardial } \\
\text { infarction who did not have } \\
\text { sustained ventricular } \\
\text { arrhythmia }\end{array}$ & US \\
\hline Death & 0.000 & 0 & N/A & Definition & N/A & N/A \\
\hline
\end{tabular}

ICD International Classification of Diseases, N/A not applicable 
Table 5 Cost-effectiveness results and events avoided over the lifetime of patients

\begin{tabular}{llll}
\hline Events per 1,000 patients & Rivaroxaban & Warfarin & Difference \\
\hline $\begin{array}{l}\text { Ischemic strokes and } \\
\text { systemic embolisms }\end{array}$ & 308 & 321 & -13 \\
Intracranial bleedings & 48 & 63 & -16 \\
Myocardial infarctions & 82 & 95 & -13 \\
Cost and effectiveness results per patient & & \\
Life-years & 10.621 & 10.510 & 0.111 \\
QALY & 8.213 & 8.119 & 0.094 \\
Costs $(€)$ & 18,695 & 17,867 & 828 \\
Incremental cost- & 8,809 per QALY gained \\
effectiveness ratio $(€)$ & \multicolumn{3}{l}{} \\
\hline
\end{tabular}

$Q A L Y$ quality-adjusted life-years

QALYs (8.213 vs. 8.119) and life-years (10.621 vs. 10.510). Over a lifetime time horizon, rivaroxaban treatment led to a reduction of 0.042 life-threatening events per patient, an increase of 0.094 QALYs and 0.111 life-years compared with warfarin treatment. This resulted in an ICER of $€ 8,809$ per QALY or $€ 7,493$ per life-year gained (Table 5). In a secondary analysis, using clinical data of ROCKET AF's intention-to-treat population, the ICER was determined at $€ 14,970$ per QALY and $€ 11,897$ per life-year gained.

\subsection{Sensitivity Analysis}

Results from the one-way sensitivity analysis indicated that the relative risk of rivaroxaban vs. warfarin for stroke, the number of $\mathrm{GP} / \mathrm{monitoring}$ visits, baseline intracranial bleed rate, and the treatment discontinuation rates were the main drivers of the cost-effectiveness analysis (Fig. 2). While, for example, the ICER was estimated at $€ 5,193$ per QALY gained should a patient on rivaroxaban no longer need to visit a physician, it would be around $€ 19,659$ per QALY if eight GP visits are required annually. Results from the PSA, based on 10,000 iterations, are presented in Fig. 3 and suggest that rivaroxaban is cost-effective compared with warfarin therapy in 66, 79, and $87 \%$ of cases if a willingness-to-pay threshold of $€ 10,000$, $€ 20,000$ or $€ 35,000$ per additional QALY were to be considered, respectively.

\section{Discussion}

The above-mentioned results suggest that, in the Belgian healthcare setting, rivaroxaban is a cost-effective alternative to warfarin for the prevention of stroke in AF patients. The incremental cost of rivaroxaban over warfarin was calculated to be $€ 828$ over the patient's lifetime in the base-case analysis. As warfarin is an off-patent drug, its drug acquisition costs are lower than these of novel innovative drugs such as rivaroxaban. This difference, however, was largely compensated by the decrease in costs related to monitoring and treatment of events. At the same time, the incremental health gain was estimated at a value close to 0.09 QALYs. These figures generate an ICER of approximately $€ 8,809 / \mathrm{Q} A L Y$ gained. Per 1,000 patients treated with rivaroxaban, an estimated 42 life-threatening events would be avoided.

One-way sensitivity analysis showed that only two variables were able to drive the ICER beyond a value of $€ 25,000$ per QALY. First, the ICER was most sensitive to the relative risk of ischemic stroke for rivaroxaban, indicating that the new treatment may not be cost-effective if it were to be associated with more strokes than warfarin. Results from the ROCKET AF trial, however, suggest that rivaroxaban (149 cases in 7,061 patients) is not less effective than warfarin (161 cases in 7,082 patients) in preventing ischemic strokes. Secondly, a higher cost of warfarin monitoring driven by more frequent visits during the maintenance phase yields a lower ICER. As its predictable anticoagulant effect makes routine monitoring redundant, patients on rivaroxaban will need to visit their GP much less frequently. Based on a report issued by the Belgian KCE [21], we have accepted there would be 15 dose monitoring/adjustment visits per year for warfarin and assumed there would be 2 for rivaroxaban. It was considered likely that the additional, regular clinical attention patients receive from their physician, independent of dose monitoring, would be comparable in both groups.

In addition, the PSA showed that the likelihood of rivaroxaban being cost-effective or even cost saving is very high. Taken together, the results of the deterministic and PSAs thus strongly support the conclusion that rivaroxaban is a cost-effective alternative to warfarin. This is in line with earlier findings from a model developed by Lee and colleagues, which already suggested that rivaroxaban therapy was cost-effective versus adjusted-dose warfarin for stroke prevention in AF in the US healthcare setting [26].

As any economic model, the present analysis has some limitations. One of the limitations was the use of a cohort Markov model for the cost-effectiveness analysis, which is limited in tracking the patient's history. For example, the risk of a second stroke is elevated over the first stroke, however this was not incorporated in the model. Another limitation of the model is that no Belgian-specific utilities could be found. However, the international values that were identified and used in the model are likely to be representative for the Belgian population because all the utility values were obtained from either a European country or the US, and from a patient population that corresponds to the Belgian population treated for stroke prevention in atrial fibrillation (SPAF) (Table 4). Moreover, it should be 


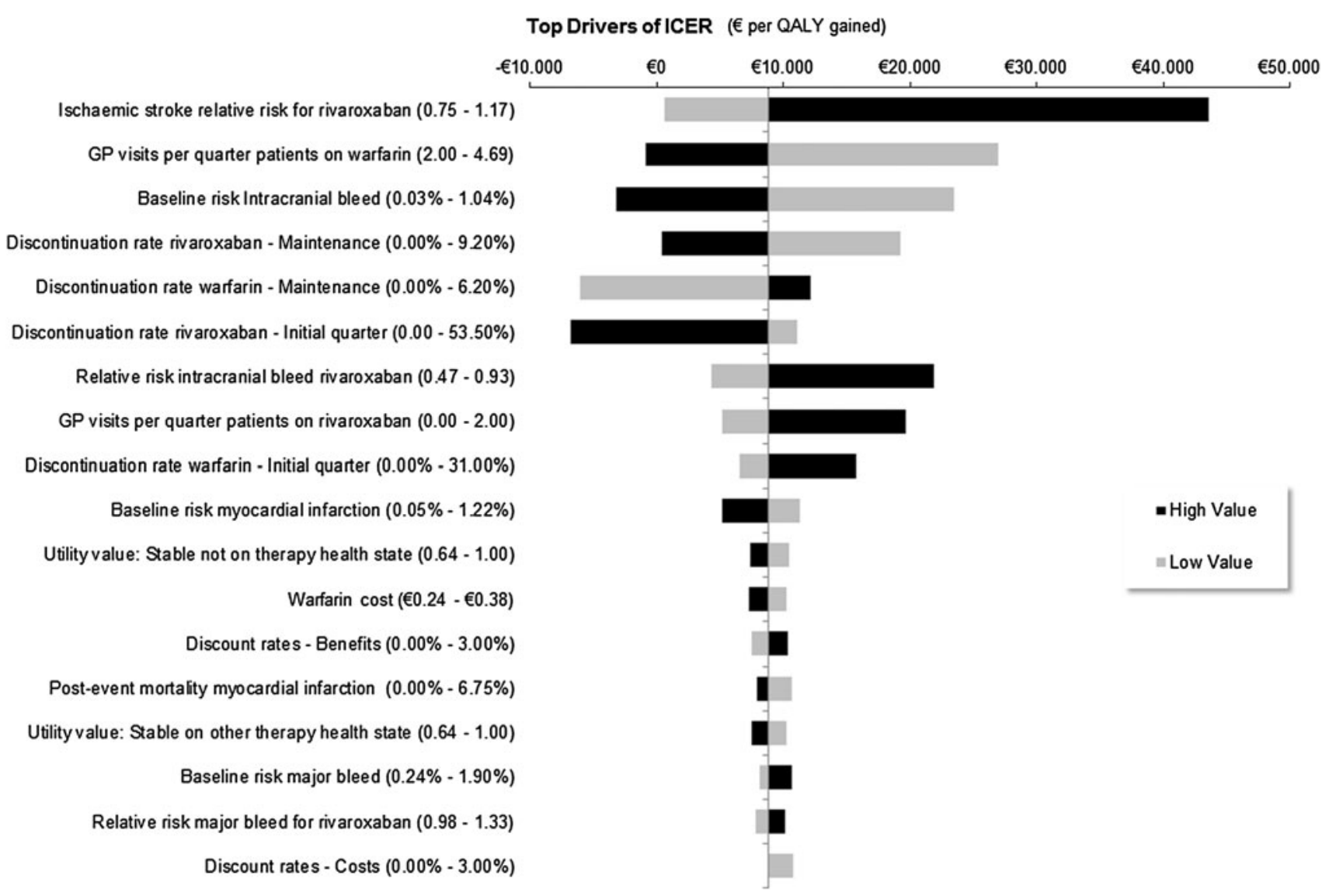

Fig. 2 Tornado diagram showing the main drivers (variables and sensitivity ranges) of the incremental cost-effectiveness ratio (ICER)

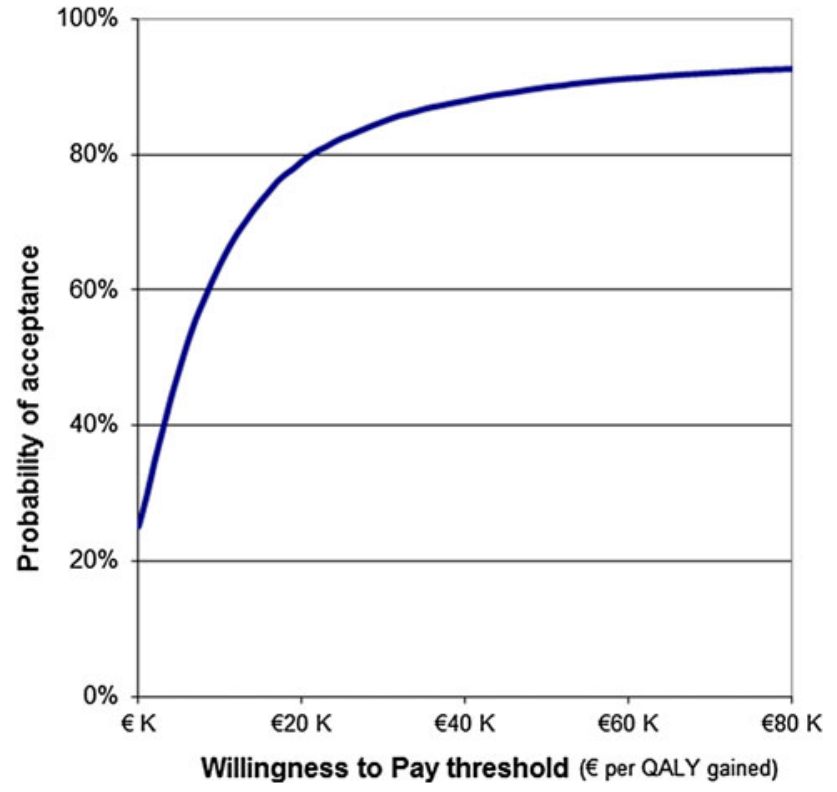

Fig. 3 Cost-effectiveness acceptability curve

noted that the ICERs were not very sensitive to changes in utility values, so this limitation would only have a minimal impact on the overall results.
A Belgian health economic study for dabigatran versus warfarin resulted also in dabigatran being considered costeffective [27], but a direct comparison between rivaroxaban and dabigatran is not possible because there are no head-to-head trials. An indirect comparison is possible [28] but not robust because of the significant differences in the study population and study design of ROCKET AF, RE-LY and ARISTOTLE. A systematic review between the three NOACs (rivaroxaban, dabigatran, apixaban) concluded that NOACs are cost-effective but the lack of head-to-head trials and the heterogeneous characteristics of underlying trials and modelling methods make it difficult to determine the most cost-effective agent [29].

Its predictable anticoagulant effects and low propensity for drug interactions gives rivaroxaban not only an economical advantage but also a major clinical advantage over VKA therapy. Because of the challenges that are associated with warfarin therapy, many Belgian patients with moderate to high risk $\left(\mathrm{CHADS}_{2}\right.$ score $\left.\geq 2\right)$ are currently being treated with aspirin $(24 \%)$ or receive no prophylaxis at all $(25 \%)$. Moreover, not all patients receiving warfarin therapy may actually get optimal anticoagulation. In fact, a cross-sectional study involving 66 general practices in Belgium showed that only $69 \%$ of the day values obtained 
over a period of 6 months fell within a target range of 0.75 INR units (1.75-3.25) [30]. In the ROCKET AF trial, however, the target range was lower (0.5 INR units; 2.0-3.0) and, consistent with this, a lower proportion of the day values $(55 \%)$ fell within the INR target range. The lower proportion of day values in the trial is likely due to the lower INR target range and can also be due to the difference in performance level of warfarin in the trial compared with real life. Since the data from the trial were used in the model, the proportion of patients who receive optimal anticoagulation therapy with warfarin might have been slightly underestimated. If that is true, this affected the ICER in favour of rivaroxaban, although this is difficult to ascertain given the difference in INR target range. Both VKA-treated and untreated patients may thus remain at high risk for stroke. In addition, the simple dosing regimen of rivaroxaban (oral, once daily) may help patients adhere to therapy, which in real life could lead to more patients reaching optimum coagulation with rivaroxaban, thereby reducing the burden of AF-related stroke.

\section{Conclusion}

The present analysis suggests that rivaroxaban is a costeffective alternative to warfarin therapy for the prevention of stroke in patients with AF in the Belgian healthcare setting.

Acknowledgements The authors would like to acknowledge Dr. Koen Putman for allowing us to use his unpublished results in our cost calculations.

This study was supported by Bayer HealthCare Pharmaceuticals. Mrs. Mimi De Ruyck, Mrs. Petra Faes, Mr. Stefaan Vansieleghem and Mr. Thomas Evers are employees of Bayer HealthCare Pharmaceuticals. Mrs De Ruyck is the author responsible for the overall content of this publication. Mr. Joris Kleintjens, Mrs. Xiao Li, and Mr. Ömer Saka were employees of Deloitte and provided consultant services to Bayer HealthCare. Ms. Yumi Asukai is an employee of IMS Health, which has received consulting fees from Bayer Healthcare. Prof. Steven Simoens, Prof. Vincent Thijs, Prof. Ernst Rietzschel, and Dr. Marnix Goethals acted as consultants to Bayer Healthcare with respect to this study.

Ms. Asukai and Mr. Evers designed the structure of and developed the global economic model. Mr. Kleintjens and Mrs. Li collected local information regarding costs, resource consumption, and utility values, adapted the model to the Belgian perspective and led the writing effort. Dr. Thijs, Dr. Rietzschel, and Dr. Goethals provided input from a Belgian perspective on clinical input data, key assumptions, and the local standard of care. Dr. Simoens was responsible for quality control of the local cost-effectiveness evaluation. Mr. Vansieleghem and Mrs. Faes conducted drug cost calculations, and contributed to the interpretation of results and writing of the manuscript. Mrs. De Ruyck and Mr. Saka coordinated the study and contributed to the interpretation of results.

Open Access This article is distributed under the terms of the Creative Commons Attribution Noncommercial License which permits any noncommercial use, distribution, and reproduction in any medium, provided the original author(s) and the source are credited.

\section{References}

1. Wolf PA, Abbott RD, Kannel WB. Atrial fibrillation: a major contributor to stroke in the elderly: the Framingham Study. Arch Intern Med. 1987;147:1561-4.

2. Marini C, De Santis F, Sacco S, et al. Contribution of atrial fibrillation to incidence and outcome of ischemic stroke: results from a population-based study. Stroke. 2005;36:1115-9.

3. Strong K, Mathers C, Bonita R. Preventing stroke: saving lives around the world. Lancet Neurol. 2007;6:182-7.

4. Mackay J, Menash GA, Greenlund K. The atlas of heart disease and stroke. Geneva: World Health Organization; 2004.

5. Devroey D, Van Casteren V, Buntinx F. Registration of stroke through the Belgian sentinel network and factors influencing stroke mortality. Cerebrovasc Dis. 2003;16:272-9.

6. Camm AJ, Kirchhof P, Lip GYH, et al. Guidelines for the management of atrial fibriliation. The Task Force for the Management of Atrial Fibrilation of the European Society of Cardiology (ESC). Eur Heart J. 2010;31:2369-429.

7. British Committee for Standards in Haematology. Guidelines on oral anticoagulation: third edition. Br J Haematol. 1998;101:374-87.

8. Bayer HealthCare. Data on file: Cegedim report 2010.

9. Evers T, O'Neil WM, Ogilvie IM, et al. PCV144-Stroke prevention in patients with atrial fibrillation: inappropriate anticoagulation and poor INR control. Value Health. 2011;14:A390.

10. Ansell J, Hirsch J, Hylek E, et al. Pharmacology and management of the vitamin K antagonists. Chest. 2008;133(suppl):S160-98.

11. Patel MR, Mahaffey KW, Garg J, et al. Rivaroxaban versus warfarin in nonvalvular atrial fibrillation. $\mathrm{N}$ Engl $\mathrm{J}$ Med. 2011;365:883-91.

12. Stuart $\mathbf{J}$, et al. Dabigatran versus warfarin in patients with atrial fibrillation. N Engl J Med. 2009;361:1139-51.

13. Granger B, et al. Apixaban versus warfarin in patients with atrial fibrillation. N Engl J Med. 2011;365:981-92.

14. Camm AJ, Lip GYH, De Caterina R, et al. 2012 focused update of the ESC Guidelines for the management of atrial fibrillation: an update of the 2010 ESC Guidelines for the management of atrial fibrillation. Eur Heart J. 2012;33:2719-47.

15. ROCKET AF Study Investigators. Rivaroxaban-once daily, oral, direct factor Xa inhibition compared with vitamin $\mathrm{K}$ antagonism for prevention of stroke and Embolism Trial in Atrial Fibrillation: rationale and design of the ROCKET AF study. Am Heart J. 2010;159:340-7.

16. Sanchez MM, Chen X. Choosing the analysis population in noninferiority studies: per protocol or intent-to-treat. Stat Med. 2006;25:1169-81.

17. US Department of Health and Human Services. Guidance for industry: non-inferiority clinical trials (draft guidance). Center for Biologics Evaluation and Research (CBER), 2010.

18. Briggs AHE, Claxton K, Sculpher M. Decision modelling for health economic evaluation. Oxford: Oxford University Press; 2006.

19. Federal Public Service Economy, SMEs, Self-Employed and Energy. Life tables Belgium 1998-2009. [Online]. http://statbel. fgov.be/nl/modules/publications/statistiques/bevolking/downloads/ bevolking_sterftetafels.jsp. Accessed 8 Jan 2013.

20. Hoit BD, Gilpin EA, Henninh H, et al. Myocardial infarction in young patients: an analysis by age subsets. Circulation. 1986;74:712-21.

21. Gailly J, Gerkens S, Van Den Bruel A, et al. Use of point-of care devices in patients with oral anticoagulation: a Health Technology Assessment. Belgian Health Care Knowledge Centre. Report number: 117C, 2009.

22. Cleemput I, Van Wilder P, Vrijens F, et al. Guidelines for pharmacoeconomic evaluations in Belgium. Belgian Health Care Knowledge Centre. Report number: 78C, 2008. 
23. Protheroe J, Fahey T, Montgomery AA, et al. The impact of patients' preferences on the treatment of atrial fibrillation: observational study of patient based decision analysis. BMJ. 2000;320:1380-4.

24. Gage BF, Cardinalli AB, Owens DK. The effect of stroke and stroke prophylaxis with aspirin or warfarin on quality of life. Arch Intern Med. 1996;156:1829-36.

25. National Institute for Health and Clinical Excellence. Rivaroxaban for the prevention of stroke and systemic embolism in people with atrial fibrillation: NICE technology appraisal guidance 256. Report number: TA256, 2012.

26. Lee S, Anglade MW, Pisacane R, et al. Cost-effectiveness of rivaroxaban compared to warfarin for stroke prevention in atrial fibrillation. Am J Cardiol. 2012;110:845-51.

27. Wouters et al. Cost-effectiveness of dabigatran etexilate in the prevention of stroke and systemic embolism in patients with atrial fibrillation in Belgium. J Med Econ. Epub 2013 Jan 22

28. HAS, Department of Medecines Assessment. Indirect comparisons methods and validity [Online] Available from: www.hassante.fr. 2009; July:35.

29. Limone et al. Novel anticoagulants for stroke prevention in atrial fibrillation: a systematic review of cost-effectiveness models. PLOS One. 2013;8(4):e62183.

30. Claes N. Quality of oral anticoagulation in patients with atrial fibrillation: a cross-sectional study in general practice. Eur J Gen Pract. 2006;12:163-8.

31. Hylek EM, Go AS, Chang Y, et al. Effect of intensity of oral anticoagulation on stroke severity and mortality in atrial fibrillation. New Engl J Med. 2003;349:1019-26.

32. Bayer Plc. Submission to National Institute for Health and Clinical Excellence: Single Technology Appraisal (STA) of Rivaroxaban (Xarelto®). 2011.

33. RIZIV/INAMI. Nomenclature codes 101010, 101032, 101076, 103110, 103132, 592815, 592830, 554573. [Online]. http://www. inami.fgov.be/homefr.htm. Accessed August 2011.
34. RIZIV/INAMI. APR DRG codes 045 and 813 - nomenclature codes 460821, 591603, 598021, 598043, 598146, 700000 766065, 766264, and 799621. [Online]. Available from: http://www. inami.fgov.be/homefr.htm. Accessed August 2011.

35. Dagres N, Nieuwlaat R, Vardas PE, et al. Gender-related differences in presentation, treatment, and outcome of patients with atrial fibrillation in Europe: a report from the Euro Heart Survey on Atrial Fibrillation. J Am Coll Cardiol. 2007;49:572-7.

36. Robinson A, Thomson R, Parkin D, et al. How patients with atrial fibrillation value different health outcomes: a standard gamble study. J Health Serv Res Policy. 2001;6:92-8.

37. Hallan S, Asberg A, Indredavik B, et al. Quality of life after cerebrovascular stroke: a systematic study of patients' preferences for different functional outcomes. $\mathrm{J}$ Intern Med. 1999;246:309-16.

38. Sullivan PW, Arant TW, Ellis SL, et al. The cost-effectiveness of anticoagulation management services for patients with atrial fibrillation and at high risk for stroke in the US. Pharmacoeconomics. 2006;24:1021-33.

39. Lenert LA, Soetikno RM. Automated computer interviews to elicit utilities: potential applications in the treatment of deep venous thrombosis. J Am Med Inform Assoc. 1997;4:49-56.

40. Haacke C, Althaus A, Spottke A, et al. Long-term outcome after stroke: evaluating health-related quality of life using utility measurements. Stroke. 2006;37:193-8.

41. Sanders GD, Hlatky MA, Every NR, et al. Potential cost-effectiveness of prophylactic use of the implantable cardioverter defibrillator or amiodarone after myocardial infarction. Ann Intern Med. 2001;135:870-83.

42. Robinson MB, Thompson E, Black NA. A model for estimating the cost-utility of clinical audit. The example of thrombolysis for suspected acute myocardial infarction. Int $\mathrm{J}$ Technol Assess Health Care. 1998;14:161-71. 